\title{
WELL-BEING AND TIME $^{1}$
}

BY

\section{J. DAVID VELLEMAN}

A person can fare well either over an extended period or at a particular moment. We evaluate how well a person fares over an extended period when we speak of him as having a good day, a good year, or a good life, or when we speak of such a period as going well for him. We evaluate how a person fares at a particular moment when we say that he is doing well just then. We favor different idioms in these two kinds of evaluation: we are more inclined to speak of a person as having a good life than as having a good moment; and, conversely, we are more inclined to use the terms 'welfare' or 'well-being' to express how well things are going for him at a particular moment than to evaluate how well his life goes as a whole. Nevertheless, evaluations of both kinds are judgments of relational value-of what's good for the person or good in relation to his interests-and so they are both judgments of the person's welfare. ${ }^{2}$

What is the relation between the welfare value ${ }^{3}$ of a temporal period in someone's life and his welfare at individual moments during that period? And what is the relation between the value of a period and that of the shorter periods it comprises? Is a good day just a day during which one is frequently well off ${ }^{4}$ Is a good week just a week in which the good days outweigh the bad? Is a good life just a string of good years?

The answer to these questions would be yes if well-being were additive. If the welfare value of a time-period in one's life were equivalent to the sum of momentary well-being that one enjoyed during that period, then a good period would indeed be a period during which one was, on balance, well off, and a good life would be a life composed, on balance, of good periods. But I doubt whether well-being is additive in this way.

Of course, I do not mean to rule out the possibility that the amount of. momentary welfare accruing to someone during his life and the welfare 
value of that life might turn out to be the same. I am simply saying that their being the same would ordinarily be an accident, because the welfare value of a life is not in general determined by, and cannot be inferred from, the amount of momentary well-being that the life contains. ${ }^{5}$

Here I am not merely denying that the value of a life can be computed by the addition of values antecedently assigned to its constituent moments. Computing the value of the whole in this manner, by composition, might be impossible only because the values of the parts had to be computed, inversely, by decomposition. If the only way to assess someone's well-being at a particular moment was to compute the fraction of his life's value that was being realized at the time, then the value of the whole would have to be computed first, and couldn't be derived from the values of the parts. ${ }^{6}$ In that case, however, well-being might still be additive in the sense that interests me, since the values of the parts and the value of the whole might still be such that the latter had to equal the sum of the former. What I wish to deny is that well-being is additive in even this sense.

My claim thus militates equally against evaluating a whole life by composition and evaluating its parts by decomposition. In my view, just as assigning values to someone's moments of existence and adding them will not necessarily yield the value of his life; so assigning a value to his life and dividing it among his moments of existence will not necessarily yield their values, either.

My strategy will be to criticize these alternative computations in turn. First I shall presuppose a rough understanding of momentary well-being, and I shall argue, on rather intuitive grounds, that the value of a life need not be the sum of the momentary well-being enjoyed within it. Then I shall argue, on more theoretical grounds, against regarding a person's well-being at a particular moment as a currently realized fraction of his life's value. In neither phase of the argument will I presuppose any particular theory of individual well-being; rather, I'll apply what I take to be commonsense notions of faring well, either over one's entire life or within the confines of a particular moment.

Intuitively speaking, the reason why well-being isn't additive is that how a person is faring at a particular moment is a temporally local matter, whereas the welfare value of a period in his life depends on the global features of that period. More specifically, the value of an extended period depends on the overall order or structure of events--on what might be called their narrative or dramatic relations. ${ }^{7}$

Consider two different lives that you might live. One life begins in the depths but takes an upward trend: a childhood of deprivation, a troubled youth, struggles and setbacks in early adulthood, followed finally by success and satisfaction in middle age and a peaceful retirement. Another 
life begins at the heights but slides downhill: a blissful childhood and youth, precocious triumphs and rewards in early adulthood, followed by a midlife strewn with disasters that lead to misery in old age. Surely, we can imagine two such lives as containing equal sums of momentary wellbeing. Your retirement is as blessed in one life as your childhood is in the other; your nonage is as blighted in one life as your dotage is in the other.

Yet even if we were to map each moment in one life onto a moment of equal well-being in the other, we would not have shown these lives to be equally good. For after the tally of good times and bad times had been rung up, the fact would remain that one life gets progressively better while the other gets progressively worse; one is a story of improvement while the other is a story of deterioration. To most people, I think, the former story would seem like a better life-story-not, of course, in the sense that it makes for a better story in the telling or the hearing, but rather in the sense that it is the story of a better life. ${ }^{8}$

Note that I am not committed to the truth of this value judgment, in particular. I offer it merely as an intuitively plausible illustration of the possibility that periods containing equal sums of momentary welfare can have different overall welfare values. (The same goes for most of the value judgments offered below.) Even those who don't agree with the present value judgment, or can imagine disagreeing with it, will at least acknowledge that it is a reasonable judgment to entertain; whereas it would be ruled out $a$ priori if well-being were additive.

One who thinks that a life's value is the sum of the momentary well-being enjoyed therein may seek to explain the outcome of this thought experiment as due to subconscious assumptions that violate the experiment's terms. That is, one may claim that a preference between lives stipulated to contain equal amounts of momentary well-being must arise from a silent refusal to grant the stipulation. Those who prefer the uphill climb to the downhill slide, one may say, are simply assuming that the highs and lows encountered in maturity are more extreme than those encountered in childhood, and that the intensifying effects of age, or mitigating effects of youth, make the goods of one life better and the evils of the other life worse.

But I doubt whether our preference between these lives can be traced to a denial of their supposed symmetry. We don't necessarily assume that the best retirement is better than the best childhood, or that the miseries of age are worse, at their worst, than the miseries of youth. If asked why we prefer the life of improvement, we would be unlikely to express such views; we would be more likely to say, "A life that gets better is, other things being equal, better than a life that gets worse." 9 We would then be expressing a preference between trends, as opposed to sums, of momentary well-being, a preference that is entirely natural and yet at odds with 
the view that a life's value is the sum of the values of its constituent moments.

This preference can be further sustained by reflection on the counterintuitive consequences of the opposing view. ${ }^{10}$ If the value of a life were additive, then a life could be forever spoiled or saved by its initial segment. Every year of well-being would raise the minimum value to which one's life could possibly fall; every year of suffering would lower the maximum value to which one's life could possibly rise. An unfortunate childhood would therefore make for a bad start in life, not only by leaving one emotionally or physically ill-equipped for future challenges, but also by permanently lowering the level of lifetime well-being to which one could reasonably aspire. Conversely, a fortunate childhood would provide not only the personal resources with which to succeed in the future but also so much lifetime well-being in the bank, so to speak, insuring the value of one's life against subsequent reverses. But surely, we do not think, after reading the first few chapters of a biography, that they have placed limits on how well or how badly the subject's life might possibly turn out. We don't think, "He's already fifteen years to the good," or ". . . fifteen years in the hole," as if registering credits or debits that will necessarily be reflected in the subject's final accounts. Yet we do think that we know how well the person fared during the first fifteen years of his life.

My remarks thus far may differ only slightly from, and add only slightly to, what Michael Slote has said in his essay "Goods and Lives." 11 There Slote offers an example closely resembling the cases I have discussed:12

A given man may achieve political power and, once in power, do things of great value, after having been in the political wilderness throughout his earlier career. He may later die while still "in harness" and fully possessed of his powers, at a decent old age. By contrast, another man may have a meteoric success in youth, attaining the same office as the first man and also achieving much good; but then lose power, while still young, never to regain it. Without hearing anything more, I think our natural, immediate reaction to these examples would be that the first man was the more fortunate . . . .

Slote goes on to say that our natural reaction to such a case "seems to suggest a time preference for goods that come late in life."

Whether Slote is describing the phenomenon that I have in mind depends on how this last remark is to be interpreted. On the one hand, a preference for goods that come late in life may reflect the view that one and the same commodity, as measured in purely descriptive terms, often adds more to one's well-being if it is received later. In that case, however, the preference in question is perfectly compatible with the view that a life's value is the sum of the momentary well-being enjoyed therein. For 
even if a particular quantity of pleasure or money or fame gives a greater boost to one's momentary welfare if it is received later in life, what the commodity adds to one's total momentary welfare, whenever it is received, may still exhaust its contribution to the value of one's life overall. On the other hand, the goods among which Slote's temporal preference discriminates might be equilibrated as goods rather than as commodities - that is, in terms of their impact on one's welfare at the time of their receipt. In that case, the preference reflects the view I am defending, that one and the same increment in one's momentary wellbeing may have greater or lesser effect on the value of one's life, depending on when and how it occurs. Although Slote sometimes appears to favor the former view, ${ }^{13}$ only the latter would place him in disagreement with Sidgwick's principle that "a smaller present good is not to be preferred to a greater future good" 14 -a principle with which Slote claims to disagree. I shall therefore interpret Slote's "pure time preference" as implying that a life's value is not equivalent to a sum of momentary well-being.

I hope to build on Slote's observations in two ways. First, I would like to suggest a deeper explanation than Slote's for the preferences cited in his article. While I agree with Slote that two benefits of equal momentary value may contribute differently to the welfare value of one's life, I doubt whether they can do so merely because of their timing. They can do so, I think, because they can belong to different life stories, which coincidentally place them at different times.

Second, I hope to draw out the consequences of this phenomenon for various issues in moral psychology and moral philosophy. Among the issues I shall discuss are the evil of death, the nature of prudence, and the value of desire-satisfaction.

Consider the theoretical conclusion that Slote hopes to illustrate with the case cited above: 15

When a personal benefit or good occurs, may make a difference to how fortunate someone is (has been), quite independently of the effects of such timing in producing other good things and of the greater importance we attach to the distinctive goals and interests of certain life periods. And I believe, in particular, that what happens late in life is naturally and automatically invested with greater significance and weight in determining the goodness of lives.

While I agree with Slote's evaluative intuitions about the case, I do not agree with this explanation of them. The reason why later benefits are thought to have a greater impact on the value of one's life is not that greater weight is attached to what comes later. Rather, it is that later 
events are thought to alter the meaning of earlier events, thereby altering their contribution to the value of one's life.

Suppose that we drew one of Slote's politicians behind a veil of ignorance about his life and put to him the following proposition. He is to have ten years of political success, but he can choose whether his fortunate decade is to occur in his fifties or his thirties. How strong a preference would he have between the alternatives thus described? I suspect that he would be indifferent. ${ }^{16}$ If he had any preference at all, it would be neither as strong nor as stable as the preference he would have if we described the alternative careers more fully, as they are described in Slote's example. Merely postponing a fixed amount of well-being until later in life wouldn't strike him as an obvious means of making it more valuable; indeed, he might reasonably regard well-being as more valuable if enjoyed in youth. Surely, then, the preference elicited by Slote's example must depend on something other than the effects of mere timing. ${ }^{17}$

In order to reproduce the preference elicited by Slote's example, we would have to tell the aspiring politician that the later successes being offered to him would be the culmination of a slow ascent, whereas the earlier successes would be the prelude to a sudden decline. That is, we would have to tell him, not only about the timing of the rewards in question, but also about their place in a larger trend. He wouldn't care whether a particular bundle of goods was to be encountered early or late in the game; what he would care about is whether they were to be encountered at the top of a chute or the top of a ladder.

Why would a person care about the placement of momentary goods on the curve that maps his changing welfare? The answer, I believe, is that an event's place in the story of one's life lends it a meaning that isn't entirely determined by its impact on one's well-being at the time. A particular electoral victory, providing a particular boost to one's current welfare, can mean either that one's early frustrations were finally over or that one's subsequent failures were not yet foreshadowed, that one enjoyed either fleeting good luck or lasting success-all depending on its placement in the trend of one's well-being. And the event's meaning is what determines its contribution to the value of one's life. ${ }^{18}$

The meaning attached to a quantity of momentary well-being is determined only in part by its place in the overall trend. ${ }^{19}$ The meaning of a benefit depends not only on whether it follows or precedes hardships but also on the specific narrative relation between the goods and evils involved. Slote's politician would have experienced an improvement in his well-being whether his years of toil were capped by electoral victory or merely cut short by his winning the lottery and retiring young. But the contribution of these alternative benefits to the overall value of his life wouldn't be determined entirely by how well-off each would make him 
from one moment to the next. Their contribution to his life's value would also be determined by the fact that the former would be a wellearned reward, and would prove his struggles to have been a good investment, whereas the latter would be a windfall in relation to which his struggles were superfluous. Thus benefits that would effect equal improvements in his momentary well-being might contribute differently to the value of his life, by virtue of lending and borrowing different meanings in exchange with preceding events.

The most familiar illustration of this principle is the commonly held belief in the importance of drawing lessons from one's misfortunes. If a life's value were a sum of momentary well-being, learning from a misfortune would be no more important than learning from other sources, since every lesson learned would add so much value and no more to the sum of one's well-being. On being invited to learn from a personal tragedy, one would therefore be entitled to reply, "No, I think I'll read a book instead." Edification would offset the losses incurred in the tragedy, but its having been derived from the tragedy wouldn't render edification more valuable, either intrinsically or extrinsically. Any lesson of equal value would offset one's losses equally. ${ }^{20}$

The point of learning from a misfortune, surely, is to prevent the misfortune from being a total loss. Learning from the misfortune confers some value on it, by making it the means to one's edification. But how could this be the point? The instrumental value of a means is not to be counted as additional to the intrinsic value of the end. (Otherwise, we would be obliged to pursue our ends as circuitously as possible, so as to accumulate the most instrumental value along the way.) Since the value of a means is not additional to that of the end, turning a misfortune into a means of learning a lesson doesn't produce any more value than that inherent in the lesson itself, a value not necessarily greater than that of any alternative lesson one might have learned. So how can the point of learning from a misfortune, in particular, be to confer instrumental value on it?

The answer, I believe, is that conferring instrumental value on a misfortune alters its meaning, its significance in the story of one's life. The misfortune still detracted from one's well-being at the time, but it no longer mars one's life story as it formerly did. A life in which one suffers a misfortune and then learns from it may find one equally well-off, at each moment, as a life in which one suffers a misfortune and then reads the encyclopedia. But the costs of the misfortune are merely offset when the value of the latter life is computed; whereas they are somehow cancelled entirely from the accounts of the former. Or rather, neither misfortune affects the value of one's life just by adding costs and benefits to a cumulative account. The effect of either misfortune on one's life is 
proportionate, not to its impact on one's continuing welfare, but to its import for the story. An edifying misfortune is not just offset but redeemed, by being given a meaningful place in one's progress through life. ${ }^{21}$

The same point can be illustrated with other examples. In one life your first ten years of marriage are troubled and end in divorce, but you immediately remarry happily; in another life the troubled years of your first marriage lead to eventual happiness as the relationship matures. Both lives contain ten years of marital strife followed by contentment; but let us suppose that in the former, you regard your first ten years of marriage as a dead loss, whereas in the latter you regard them as the foundation of your happiness. ${ }^{22}$ The bad times are just as bad in both lives, but in one they are cast off and in the other they are redeemed. Surely, these two decades can affect the value of your life differently, even if you are equally well off at each moment of their duration. From the perspective of your second marriage, you may reasonably think that your life would have gone better if you could have made your first marriage work out; and you may reasonably think so without thinking that the first marriage, if successful, would have been better from day to day than the second. You can simply think that a dead-end relationship blots the story of one's life in a way that marital problems don't if they lead to eventual happiness.

Of course, your desire for a successful first marriage is fulfilled in the latter life, whereas in the former it is given up and replaced by the desire for a successful second marriage. In a sense, then, the former life differs from the latter by virtue of containing more unfulfilled desires. Doesn't this difference in desire fulfillment explain the difference in perceived value between these lives?

I doubt whether a difference in desire fulfillment can do this explanatory job. Suppose, for example, that in both versions of the story your early desire to achieve happiness with your first mate was accompanied by an equally strong, competing desire to start afresh with someone else. The only difference between these desires, let us say, was that during your ten years of trying to fulfill the former, the latter remained an idle yearning on which you never acted. Now the two endings of your story no longer differ in respect to the fulfillment of your youthful desires: each ending fulfills one and frustrates one of the desires that you harbored throughout your first marriage. Do they consequently result in equally valuable lives? I am inclined to say not. For I am still inclined to prefer the ending in which your initial efforts are redeemed over the ending in which they are abandoned. Fulfilling a desire on behalf of which you have struggled may be more important than fulfilling a desire in which you have made no investment. Hence desire fulfillment per se is 
not what's valuable; what's valuable is living out a story of efforts rewarded rather than efforts wasted. ${ }^{23}$

Insofar as the fulfillment of one's past desires is valuable, I am inclined to say, its value depends on that of life stories in which desires are eventually fulfilled. For I cannot see how a difference in the fulfillment of past desires can yield any difference in momentary well-being. Let us cancel the assumption that you always wanted to change mates, and return to the assumption that the beginning of your story, in either version, includes only a desire to make a go of your first marriage-a desire that's fulfilled in one version but abandoned in the other. The question remains when you are rendered worse off, in the version that involves a second marriage, by the abandonment of your hopes for the first. Once you abandon those hopes, you acquire new ones-for success in the second marriage-and these are richly fulfilled. You are therefore just as well off in your second marriage, from day to day, as you would have been in your first, had it flourished. To be sure, you are no longer achieving what your former self wanted you to achieve-namely, success in the first marriage-but this failure can hardly make your former self worse off retroactively. The daily well-being of your former self is a feature of the past, beyond alteration. Failure to fulfill your previous desires thus impinges on your interests without affecting your welfare at any particular moment.

Oddly enough, several philosophers have affirmed the possibility of retroactive effects on well-being-often in order to explain when a person suffers the evil of death. ${ }^{24}$ According to these philosophers, a person's death can make him worse off during the immediately preceding portion of his life, by preventing the fulfillment of the desires he has during that period.

These philosophers argue that our resistance to the idea of being currently harmed by future events is based on the false assumption that one cannot be harmed by things that don't affect one's conscious experiences. But acknowledging the possibility of unexperienced harms should not necessarily lead us to acknowledge the possibility of present harms due to future events. For even if a person's current welfare is not determined entirely by facts within his experience, it may still be determined entirely by facts within the present.

This restriction on the determinants of momentary well-being cannot be inferred directly from the impossibility of backward causation. Future events could affect one's present well-being if present well-being were a relation between one's present desires and the states of affairs that fulfilled or failed to fulfill them. In that case, retroactively harming someone would no more require retrograde causation than retroactively "making a liar" of him. But momentary well-being is ordinarily conceived as a temporally local matter, determined by a person's current circumstances, whether experienced or unexperienced. We think of a 
person's current well-being as a fact intrinsic to the present, not as a relation that he currently bears to his future. We don't say, of a person who dies in harness, that he fared progressively worse toward the end, simply because he was acquiring more and more ambitions that would go unfulfilled. Nor do we say, of a person raised in adversity, that his youth wasn't so bad, after all, simply because his youthful hopes were eventually fulfilled later in life. ${ }^{25}$ We might say that such a person's adulthood compensated for an unfortunate youth; but we wouldn't say that it made his youth any better. Because the belief in retroactive welfare effects would entail such judgments, it strikes me as highly counterintuitive.

Thus, the reason why it is generally in your interests to promote the fulfillment of your current desires for the future cannot be that their future fulfillment will make you better off now. Nor can it be that their future fulfillment will make you better off then-that is, better off than you would be if you replaced them with different desires that got fulfilled. ${ }^{26}$ The reason why it is in your interests to promote the fulfillment of your current desires for the future is rather that a life story of ambitions conceived, pursued, and fulfilled may be a better life story than one of ambitions conceived, discarded, and replaced. And the one life is better than the other even though they may include equal amounts of momentary well-being. ${ }^{27}$

My view of lifetime well-being provides a different explanation from Slote's for the discrepancy in our attitudes toward early and late stages in life. My explanation begins with the observation that events in a person's life can borrow significance from both preceding and succeeding events. A particular success can be either a windfall or a well-earned reward, depending on the amount of effort that preceded it; the expenditure of a particular effort can be either a good investment or a waste, depending on the degree of success that ensues. Retrospective significance-that which is gained from subsequent events-is often responsible for the discrepancy between total momentary well-being and lifetime value. For when subsequent developments alter the meaning of an event, they can alter its contribution to the value of one's life, but they cannot retroactively change the impact that it had on one's well-being at the time.

From the perspective of practical reasoning, in which the past is fixed but the future remains open, earlier events seem more susceptible to retroactive changes of significance. Even after the events of one's youth have occurred, their import for one's life story remains undetermined, since the events from which they will gain significance or to which they will lend significance lie primarily in the future. By contrast, the events of one's old age occur in the determinate context of one's past, with which they exchange fixed implications that are unlikely to be significantly modified in what remains of one's life. Thus, one looks forward 
to a lifetime in which to redeem one's youth, but confronts events of middle age as having a single, determinate significance once and for all.

The result is, not that later events are more important, but that one sees less latitude for arranging them within the requirements of a good life. By middle age, one finds oneself composing the climax to a particular story-a story that is now determinate enough to be spoiled. Virtually any beginning might have been the beginning of a good life; but given one's actual beginnings, there may now be only a few good ways of going on. ${ }^{28}$

Because one will confront one's prime with relatively narrow criteria of success, one is required to devote more care to planning it and to ensuring that it turns out as planned. The extraordinary attention paid to this stage in life may be misinterpreted as indicating that it is more important-that the events of middle age contribute more to a life's value than events at other stages. The reason for paying more attention to one's prime, however, is not that the possibilities at middle age are worth more than at other stages but rather that in relation to a fixed youth, fewer of the possibilities will result in a life that's any good at all.

My account of the value judgments canvassed above amounts to the claim that the value of one's life is what might be called a strongly irreducible second-order good. ${ }^{29} \mathrm{~A}$ second-order good is a valuable state of affairs consisting in some fact about other goods. Of course, corresponding to every good that someone might attain is the potential fact of his having thereby attained something good; and his having attained something good would undeniably be a good state of affairs consisting in a fact about other goods. There is therefore a second-order good corresponding to every attainable good of the first order. But such a secondorder good is reducible to the first-order good implicated in it, in the sense that it has no value over and above that of the implicated firstorder good. That is, when someone attains a good, he is not enriched by its value plus some additional value attaching to the fact of his having thereby attained something good. (If he were, then he would be infinitely enriched, since the second-order good would generate a good of the third order, and so on ad infinitum).

In order for a second-order good to be irreducible, it must at least possess value over and above that of its component first-order goods. A possible example of such a good in the realm of social value is that of a just distribution of benefits. Some people think that there can be value in redistributing benefits among the members of a society even if the redistribution doesn't increase the total amount of good accruing to individuals. This thought implies that the resulting distribution has a value over and above that of the goods being distributed, and hence that the new distribution is an irreducible second-order good. 
There is yet a stronger form of irreducibility that may or may not attach to a second-order good whose value is additional to that of its components. Consider two possible views about the second-order value of a just distribution. On the one hand, we might judge that a distribution of individual benefits has a second-order value that depends entirely on the proportions among the shares of benefits distributed; on the other hand, we might judge that the justice of a distribution, and hence its value, depends on whether individuals deserve their shares by dint of their actions or characters. The first view implies that the value of a just distribution, though additional to that of the benefits distributed, can still be computed from the amounts in which those benefits are distributed. The view thus implies that facts about second-order value are still, in a sense, reducible to facts about mere quantities of first-order goods. By contrast, the second view implies that no facts about quantities of first-order goods can fully determine the facts about second-order value, since the latter also depend on facts about the conduct and characters of individuals. The second view thus implies that the secondorder value of a just distribution is irreducible in a stronger sense.

The existence of second-order goods that are irreducible in either sense entails the existence of more than one dimension of value. If social justice is an irreducible second-order good, for example, then there must be a dimension of value other than total individual welfare-a dimension of social value, as it might be called-along which value can be produced even while total individual welfare remains constant.

In the case of distributing benefits among the periods in someone's life, however, the corresponding implication may initially seem odd. If we regard a particular temporal distribution of well-being as having irreducible second-order value for a person, we would seem committed to claiming that its value lies along a dimension distinct from that of total individual well-being, since we shall have said that value can be produced by a redistribution that leaves total well-being constant. Yet the distribution in question is supposed to be good specifically for the person, and so its value would seem to lie along the dimension of individual wellbeing rather than along any alternative dimension. We are therefore confronted with a puzzle. If a temporal redistribution of benefits produces no additional benefits for the person, how can it be beneficial to him? How can a person be better off under an arrangement that affords him no additional benefits?

The answer to this question is that the value of a temporal distribution of benefits needn't lie along a dimension of value distinct from that of individual well-being; its dimension of value must be distinct only from that of momentary individual well-being, since momentary benefits are 
the benefits whose total remains constant under the envisioned redistribution. Thus, regarding a temporal distribution of benefits as an irreducible second-order good requires the assumption that a person's well-being has both a synchronic and a diachronic dimension. The value of someone's life lies along the dimension of diachronic welfare, which is distinct from, and irreducible to, how well off he is at each moment therein.

Here we find, in a new guise, the value judgment with which I begannamely, that two lives containing equal sums of momentary well-being need not be equally good lives if their momentary benefits stand in different temporal or, more generally, different narrative relations. We can now see what this intuitive judgment implies: it implies that selfinterest is not a unitary dimension of value. Rather, a person has two distinct sets of interests, lying along two distinct dimensions-his synchronic interests, in being well off at particular moments, and his diachronic interests, in having good periods of time and, in particular, a good life.

Although Slote regards a life's value as weakly irreducible, he doesn't regard it as irreducible in the stronger sense. ${ }^{30}$ Slote analyzes the values of lives in terms of weights assigned to momentary goods in accordance with the time of their occurrence. He says that some periods of life are more important than others, and hence that the goods and evils occurring in those periods are accorded greater weight when the value of a life is computed. His view therefore amounts to the claim that facts about the value of a life can be reduced to facts about the amounts and temporal order of the momentary benefits enjoyed therein-in short, to facts about temporal patterns of momentary benefits.

In my view, however, the facts about a life's value are not even reducible to this extent. Some of the value judgments considered above are incompatible with any reduction of diachronic well-being to synchronic well-being, no matter how sophisticated an algorithm of discounting and weighting is applied. Because an event's contribution to the value of one's life depends on its narrative relation to other events, a life's value can never be computed by an algorithm applied to bare amounts of momentary well-being, or even to ordered sequences of such amounts, in abstraction from the narrative significance of the events with which they are associated. How the value of one's life is affected by a period of failure combined with a period of success, for example, cannot be computed merely from the timing of these periods and the amounts of well-being they contain. Their impact on the value of one's life depends as well on the narrative relations among the successes and failures involved. Were one's travails in the political wilderness ended by ascent to high office? or were they ended by a lucky ticket in the lottery and a 
round-the-world cruise? Was one's perseverance through rocky times vindicated or discredited by the particular way in which one eventually attained domestic happiness? Our evaluative intuitions about the importance of learning from misfortunes, or of salvaging one's projects, thus imply that the value of a life is more strongly irreducible than Slote suggests.

The degree of irreducibility between second- and first-order goods determines the degree of independence between the corresponding dimensions of value. If we analyze the second-order value attaching to different patterns of benefits in terms of weights attached to those benefits, we shall continue to regard diachronic well-being as reducible to synchronic well-being, albeit by means of a time-weighted algorithm. The implication will therefore remain that the greater weight attached to some goods and evils, because of their occurring at important times, can be offset by a greater amount of goods and evils occurring at times of less importance. The second-order value of a benefit's timing will thus be conceived as exchangeable for a greater amount of that or any other first-order benefit.

Thus, if the problem with a downward trend in well-being were that more importance attached to what happens in one's prime, then there would have to be some amount of childhood happiness that was sufficient to compensate for midlife misfortunes even after the appropriate weights had been applied. Childhood well-being would still amount to so much credit earned toward a good life, even if that credit was computed at a discounted rate. Hence a life that took a slide would still be a good one if it started from a sufficient height.

If we suppose, however, that the second-order value of a life is simply not computable from the amounts and temporal order of the momentary benefits that it contains, then we must conclude that some second-order goods may not be exchangeable for goods of the first order (and vice versa). That is, there may be some undesirable turns of plot whose disvalue simply cannot be offset by greater amounts of momentary wellbeing in the associated prelude or denouement. I find this implication more consonant with our evaluative intuitions than the implications of Slote's view. It explains why we think that the value of someone's life remains almost entirely undetermined even after he has passed an especially happy or unhappy childhood; and why we are inclined to perceive some wisdom in Solon's refusal to declare Croesus happy without knowing how his life would ultimately turn out. ${ }^{31}$

I therefore favor the principle that a person's self-interest is radically divided, in the sense that he has an interest in features of his life that aren't at all reducible to, and hence cannot be exchanged with, patterns 
of momentary well-being. Let me briefly suggest two possible applications for this principle.

First, I think that this principle, if correct, justifies a revision in the philosophical conception of prudence and imprudence. ${ }^{32}$ Imprudence has traditionally been conceived as an irrational preference for momentary goods that are closer in time, and prudence as a rational indifference toward the timing of such goods. Prudence and imprudence have thus been conceived as dispositions to value momentary goods differently. In my view, however, we should consider the hypothesis that imprudence is rather an undue concern for momentary goods altogether; and prudence, a rational appreciation for the second-order value of a good life-a disposition that cannot be constituted out of any appreciation for patterns of momentary goods. According to this hypothesis, a person can be imprudent no matter how carefully he balances momentary goods of the present against those of the future, if he does so without regard to the value of the resulting life, a value not reducible to temporal distributions of momentary goods; and a person can be prudent even if he pursues present benefits at the expense of future benefits, so long as the value of his life is thereby enhanced. Preferring the lesser but nearer good to that which is greater but more remote may sometimes be the prudent thing to do, if done in the service of one's irreducible secondorder interest in a good life.

A second application for the principle of divided self-interest has to do with the evil of death. A prevalent view about death is that it is bad for a person if, but only if, his continued survival would add to his accumulation of momentary well-being. The choice between heroic medical treatment and passive euthanasia is therefore frequently said to require so-called quality-of-life considerations. Whether days should be added to or subtracted from a patient's life is to be judged, according to the prevalent view, by whether the days in question would be spent in a state of well-being or hardship. ${ }^{33}$

In my view, however, deciding when to die is not (despite the familiar saying) like deciding when to cash in one's chips-not, that is, a decision to be based on the incremental gains and losses that one stands to accumulate by staying in the game. It is rather like deciding when and how to end a story, a decision that cannot be dictated by considerations of momentary well-being. Hence a person may rationally be willing to die even though he can look forward to a few more good weeks or months; ${ }^{34}$ and a person may rationally be unwilling to die even though he can look forward only to continued adversity. The rationality of the patient's attitude depends on whether an earlier or later death would make a better ending to his life story.

Thus far I have presupposed a prior understanding of what it is to be well 
off at a particular moment, and I have argued that the value of a person's life is not reducible to his momentary well-being, so understood. The reader might be moved to object, however, that I am not entitled to my initial presupposition. One might think that the only legitimate conception of a person's well-being is that of his life's value; and that any conception of his well-being at a particular moment must therefore be illegitimate insofar as it fails to capture the portion of his life's value being realized at that moment.

I shall argue against this suggestion on grounds more theoretical than those of my previous arguments. First I shall offer a more theoretical explanation of why a person's momentary well-being might fail to be additive. The reason, I shall claim, is that a person's well-being at each moment is defined from the perspective of that moment, and values defined from different perspectives cannot necessarily be added together. This explanation will prompt the suggestion that the successive perspectives defining momentary well-being simply distort the true values of things, which are properly defined from the comprehensive perspective of an entire life. I shall then argue against this suggestion, by defending the independent validity of momentary perspectives. Finally, I shall explore some further implications of these theoretical results.

That momentary well-being might not add up should come as no surprise: values are rarely additive. Notoriously, the value of two things together need not be the sum of their individual values. ${ }^{35}$ The value of having two egg rolls on one's plate is less than the sum of the values of having one or the other of them; and the value of having one egg roll and a dollop of plum sauce is more than the sum of the values of having either an egg roll or plum sauce alone. To be sure, the value of having two egg rolls is indeed the sum of their marginal values: marginal values are additive. But marginal values are additive only because they are defined by decomposition of total value, to begin with. That is, the marginal value of one's second egg roll is defined as the amount by which its acquisition increases one's total well-being; and this definition guarantees that the acquisition of a second egg roll increases one's wellbeing by the addition of its marginal value. The point previously made by saying that the values of egg rolls aren't additive can then be made by saying that the marginal values of two successive egg rolls aren't the same.

Of course, what's currently at issue is not additivity in the value of some commodity such as food but additivity in well-being itself. The question is not whether two egg rolls are twice as good as one but whether being well off at two different times is twice as good as being well off at one time. And we might have thought that although successive 
helpings of food can vary in their impact on one's well-being, and hence in their marginal value, successive helpings of well-being cannot.

This thought might have been correct if the helpings in question were defined in relation to the same context of evaluation. But since helpings of momentary well-being are defined in relation to different contexts, they aren't additive at all. Let me explain.

The reason why the marginal value of successive egg rolls varies is that the value of acquiring an egg roll depends on the context in which the acquisition occurs. One's second egg roll is worth less than the first because it is acquired in the context of one's already having the first. Of course, once the second egg roll is assigned a marginal value, that value needn't be further adjusted because of its being acquired in the context of the well-being that's already, so to speak, on one's plate; the egg roll's marginal value already reflects the only adjustment necessitated by the context.

Nevertheless, we often restrict the context in which judgments of value are made. For example, we make distinct assessments of how well off someone is in different respects-assessments of his financial well-being, say, or his emotional well-being, and so on. And such evaluations are made within restricted contexts. An assessment of someone's financial well-being may take account of the diminishing marginal value of dollars: ${ }^{36}$ his second million needn't be thought to make him twice as well off, financially speaking, as the first. But our assessment of someone's financial well-being does not take account of interactions between his finances and other goods. The impact of a million dollars on someone's overall well-being may depend not only on how much wealth he already has but also on his emotional state or his health. But the potential interactions between wealth and these other goods are screened off from assessments of specifically financial well-being. Two people with equal assets and liabilities (and, perhaps, similar attitudes towards money) are judged to be equally well off, financially speaking, even if those assets and liabilities affect their overall welfare differently, by virtue of their differing emotional or physical circumstances. ${ }^{37}$

Consequently, we cannot compute a person's overall well-being at a particular moment by adding up his concurrent financial well-being, emotional well-being, physical well-being, and so on. The problem is not simply that we don't know how to commensurate among wealth, health, and sanity - that is, how to bring these commodities under a common unit of value for the purposes of addition and subtraction. The problem is that such restricted assessments of well-being are made in isolation from potential interactions among the goods involved. Our assessment of the person's financial well-being doesn't reflect how his emotional and physical circumstances affect the marginal value of his wealth; our assessment of his emotional well-being doesn't reflect how his physical 
and financial circumstances affect the marginal value of his sanity; and so forth. Thus, even if we could establish an equivalence of value between a helping of financial well-being and a helping of physical wellbeing, we wouldn't have established that the combination of the two was worth twice as much as either one alone, since our measures of financial and physical well-being would not reflect potential interactions between the values of the underlying commodities.

We can easily forget this limitation on evaluative calculations if we imagine value itself to be a commodity. If we picture financial well-being as an elixir distilled from piles of money, we shall think of it as having an independent existence; and we shall then be inclined to think that when financial well-being is added to the values distilled from physical health or emotional stability, the resulting brew must simply be the sum of its ingredients. But an amount of financial well-being is not a quantity of stuff; it is rather a property of one's financial state. Indeed, it's a property that one's financial state possesses only in relation to other possible financial states, just as one's overall well-being at a particular moment is a relation of one's overall state to the other states that one might be in. And there is no reason to assume that the relation of one's overall state to its possible alternatives can be computed from the relations of its parts or aspects to theirs.

The problem of compounding values is analogous, in many respects, to problems in the compounding of chances. Notoriously, the probability of a person's having the trait $p$ or $q$ is not necessarily equal to the probability of having $p$ plus that of having $q$, since the latter probabilities may not be independent; and for the same reason, the probability of having the trait $p$ and $q$ is not necessarily equal to the product of the probabilities of having the component traits. Consequently, we cannot estimate how unusual a person is by compounding the degrees to which he is physically unusual, psychologically unusual, socially unusual, and so on. The product of these probabilities may not reflect the extent to which the person possesses physical and psychological traits that are individually rare but often combined, or vice versa. This computation would therefore count someone with red hair and a hot temper as doubly unusual, ${ }^{38}$ even if these two unusual traits tend to go hand in hand; and it would correspondingly underestimate the rarity of someone who is both beautiful and modest. In estimating how physically unusual a person is, we do take account of interactions among the probabilities of physical traits (red hair and freckles); in estimating how psychologically unusual he is, we take account of interactions among the probabilities of psychological traits (hot temper and romantic passion); but in neither case do we consider interactions between physical and psychological probabilities. Because these estimates of probability are thus confined to different contexts, they cannot be added or multiplied together. 
In short, calculating someone's overall well-being by adding up his physical and emotional welfare is no more appropriate than calculating how unusual he is by compounding his physical and emotional quirkiness. My view is that momentary well-being lacks additivity for the same reasons. Estimates of momentary well-being are made within a restricted context-namely, the context of the events and circumstances of the moment. How well off someone is judged to be at one moment doesn't reflect potential interactions between the value of what obtains and happens then and the value of earlier or later events. Hence evaluations made in the context of one moment cannot be added to evaluations made in the context of another. Being well off on two occasions doesn't necessarily make a person doubly well off, any more than being both physically and psychologically unusual makes him doubly unusual. ${ }^{39}$

Again, we shall tend to forget this limitation on evaluative calculations if we imagine an amount of momentary well-being as a quantity of stuff, derived from the facts of the moment but then having an independent existence of its own. In reality, one's well-being at each moment is a relation between the facts of the moment and alternative possibilities; and there is no reason to assume that the relations of successive facts to their alternatives determine the relation of the entire succession to its alternatives.

My claim that momentary well-being is assessed from a restricted perspective might seem to undermine my earlier claim that a person's selfinterest is divided. Doesn't my latest argument show that a person's synchronic interests are divided from his diachronic interests only in the sense that his financial interests, say, are divided from his interests as a whole? Either division, one might think, is merely an artifact of the restrictions placed on the context in which synchronic or financial interests are assessed: a person's interests, comprehensively considered, are still unified.

Although I agree that the division between synchronic and diachronic interests results from the difference between the perspectives from which they are assessed, I hesitate to assume that the more comprehensive of these perspectives has exclusive authority. In the case of a person's financial interests, of course, I am inclined to say that insofar as they diverge from his interests overall, they should be regarded as a figment of a restricted perspective and should be ignored. Although a person can limit his attention and concern to financial matters from time to time, the resulting value judgments, even if correct, have no independent authority on which to stand in competition with more comprehensive judgments of his interests.

A person's synchronic interests, however, strike me as having an independent claim that is not necessarily overridden by that of his diachronic 
interests. The reason, I think, is that a person himself has both a synchronic and a diachronic identity. The perspectives from which synchronic interests are assessed, unlike the financial perspective, are not optional points of view that a person may or may not adopt from time to time. They are perspectives that a person necessarily inhabits as he proceeds through life, perspectives that are partly definitive of who he is. An essential and significant feature of persons is that they are creatures who naturally live their lives from the successive viewpoints of individual moments, as well as from a comprehensive, diachronic point of view.

To think that the more comprehensive of these perspectives must have greater authority is, I believe, to mistake how perspectives bear on questions of relational value. When we choose between competing theories about one and the same phenomenon, the more comprehensive theory may be preferable, other things being equal. But the different perspectives currently in play aren't competing theories about the same phenomenon; they're partly constitutive of different phenomena-that is, different modes of relational value. Because well-being is a relational value, it is constituted, in part, by a point of view-namely, the point of view inhabited by the creature whose well-being is in question. What's good for that creature, in particular, depends on what point of view it inhabits by virtue of being the particular creature it is.

Thus, although the perspective of a particular creature is less comprehensive than that of the entire universe, evaluations relative to the creature's perspective aren't any less authoritative than those relative to the universe's point of view. Evaluations relative to a particular creature's perspective are authoritative about what's good for that creature; and what's good for a particular creature is really and truly good for that creature, even if it isn't good for the universe. These two perspectives aren't two competing theories about one and the same mode of value; they're constitutive of two different modes of value.

Similarly, evaluations from the perspective of a single moment in someone's life needn't be less authoritative than those which are relative to the perspective of his life as a whole. Both are judgments of relational value, which is constituted in either case by a particular point of view; and evaluations relative to either point of view are authoritative about what's good from that point of view.

The question, then, is not whether what's good from the perspective of a moment in someone's life is really good, since it really is good from that perspective. The question is rather whether the perspective in question has a subject-whether there really is a creature whose perspective it is and who therefore is the subject of the values it constitutes. To this latter question, I think, the answer is yes. By virtue of being who you are, you unavoidably occupy successive momentary viewpoints as well as a diachronic one; and just as what's good from the latter view- 
point is good for you as protagonist of an ongoing life, so what's good from the former viewpoints is good for you as subject of successive moments within that life. ${ }^{40}$

Note that in arguing for the validity of synchronic perspectives, I am not defending or attacking any thesis about time preferences. ${ }^{41} \mathrm{I}$ am not trying to show that one is entitled to take a greater interest in the present moment than in other moments in one's life. In my view, no one momentary perspective takes precedence over any other. My brief is on behalf of all momentary perspectives equally, against the assumption that their deliverances are to be overridden by those of the diachronic perspective that subsumes them. I am trying to show that the value something has for someone in the restricted context of a single moment in his life is a value that genuinely accrues to him as the subject of that moment, even if interactions with events at other times result in its delivering a different value to him in his capacity as the protagonist of an entire life. The good that something does you now is not just the phantom of a restricted method of accounting; it's an autonomous mode of value.

If I am right about the autonomy of synchronic interests, then a person's well-being at a particular moment cannot be computed from the fraction of his life's value being realized at the time, any more than the value of the whole can be computed from the values of its parts. To assess the benefits that someone is currently receiving in terms of their share in the value of his life would be to evaluate everything in the more comprehensive context. Such a method of evaluation might be appropriate for Tralfamadorians, who don't live one moment at a time, ${ }^{42}$ but it isn't appropriate for human beings. Just as evaluating a life by adding up the values of its component moments entails neglecting the perspective that encompasses the unity of those moments, so evaluating moments in a life by dividing up the value of the whole entails neglecting the perspectives that preserve their individuality. Each moment in a life is, momentarily, the present. And for a human being, the present is not just an excerpt from a continuing story, any more than the story is just a concatenation of moments. ${ }^{43}$

What if a creature cannot adopt a perspective that encompasses a particular combination of goods? How then do we assess what value the combination has for him or how the values of its components interact?

Consider a nonhuman animal, such as a cow or a pig. I assume that a cow cannot conceive of itself as a persisting individual and consequently cannot conceive of itself as enjoying different benefits at different moments during its life. What the cow cannot conceive, it cannot care about; and so a cow cannot care about which sequences of momentary goods it enjoys. The cow cannot care twice as much about faring well at 
two distinct times than it cares about faring well right now-not because it can care only less than twice as much, but rather because it cannot care at all, being unable to conceive of itself as persisting through a sequence of benefits.

The upshot is that any judgment we make about the value that a particular sequence of benefits has for a cow will bear no relation to how the cow would or should or even could feel about that sequence of benefits. And this result seems incompatible with even a weak form of internalism about value, which would at least rule out the possibility that something can be intrinsically good for a subject if he is constitutionally incapable of caring about it. I am not sympathetic to stronger versions of internalism, which make a thing's intrinsic value for someone contingent on his being disposed to care about it under specified or specifiable conditions; but I am inclined to think that unless a subject has the bare capacity, the equipment, to care about something under some conditions or other, it cannot be intrinsically good for him. ${ }^{44}$

Of course, we can adopt yet a weaker form of internalism, which allows for intrinsic goods that the subject cannot care about, so long as they are compounded out of goods that he can. But this version of internalism will be unstable, for two reasons.

One reason is that this version will commit us to constrain some of our judgments about intrinsic relational value within the bounds of internalism and yet to make other, similar judgments that exceed the same bounds. If we assume that what cannot be of concern to a creature can nevertheless have intrinsic value for that creature, provided that it is divisible into components that can be of concern, then we shall need to adopt some method for combining the values of the components. In order to add up the momentary goods enjoyed by a cow, for example, we shall have to make some assumption about how the values of those goods interact, so that we can compute their combined value. And this assumption will constitute another judgment of intrinsic relational value. To suppose that a cow's momentary well-being consists in this or that feature of its current circumstances is one value judgment; but to suppose that the values of the cow's good moments can be combined in this or that way is a further value judgment, a judgment to the effect that two moments containing the relevant feature are this much or that much better for the cow than one.

Whether we say that one moment of such-and-such a kind is good for a cow, or that two such moments are thus-and-so much better for the cow, we are making a judgment of intrinsic relational value. Yet the proposed version of internalism will say that the validity of the former judgment depends on the cow's ability to care about the object of evaluation, whereas the validity of the latter does not. On what grounds can this distinction be drawn? Surely, whatever intuitive reasons we have for 
applying the internalist constraint to the first value judgment are likely to be reasons for applying it to the second.

Another, related instability in the resulting view is that it is at odds with a fundamental intuition about relational value-namely, that the value something has for a particular creature is somehow grounded in or determined by that creature's point of view. ${ }^{45}$ Insofar as we commit ourselves to combining the values accruing to a subject from goods whose combinations exceed his comprehension, we shall find ourselves making relational value judgments that are not appropriately related to the subject's perspective. There is nothing about the perspective of a cow that supports one assumption rather than another about how the value of two momentary benefits stands to the value of either benefit alone, given that sequences of such benefits are beyond the cow's ken and thus, as it were, nothing to the cow. The combined value would therefore have no claim to represent what's good for the cow, or what's good from the cow's perspective. ${ }^{46}$

Note that this problem is equally acute for all possible assumptions about how the cow's momentary benefits should be combined. Even the assumption that two equally good moments in the cow's life are twice as valuable as one presupposes a flat curve of marginal value; ${ }^{47}$ and this presupposition has no basis in the cow's point of view. Such a straightforward method of adding benefits may have the advantages of simplicity and salience in comparison with other methods, but these advantages shouldn't be mistaken for truth. In respect to truth, any method of combining the values of a cow's good and bad moments will be purely arbitrary and consequently defective, insofar as it fails to represent what values things have specifically for the cow rather than from some other perspective.

I therefore think that we should refuse to combine the momentary benefits and harms accruing to a cow; we should conclude, instead, that a cow can fare well or ill only at particular moments. Good and bad things can befall a cow, but they are good or bad for it only at particular times and thus bear only a time-indexed sort of value. There is no timeless dimension of value along which the cow progresses by undergoing successive benefits and harms. Hence the various benefits accruing to a cow at different moments must not add up to anything at all, not even to zero: they must simply be unavailable for addition.

As before, if we imagine the cow's momentary well-being as a commodity, then we shall be puzzled by the claim that amounts of this commodity cannot be added together. But once we realize that the cow's momentary well-being is a relation that the cow's current state bears to other possible states, the air of mystery is dispelled. For there is nothing odd about the suggestion that a relation obtaining between momentary states of a cow cannot obtain between sequences of those states. One 
moment can be better or worse for a cow than another moment, but one sequence of moments cannot be better for a cow than another sequence, because a cow cannot care about extended periods in its life. This conclusion seems mysterious only if we imagine one moment as better for the cow than another by virtue of containing more of a special stuff that cannot help but accumulate.

For a lower animal, then, momentary well-being fails not only of additivity but of cumulability by any algorithm at all. Consequently, the totality of this subject's life simply has no value for him, because he cannot care about it as such, and because its constituent moments, which he can care about, have values that don't accumulate.

This conception of a lower animal's interests is supported, I think, by its fruitfulness in accounting for our intuitions about the moral difference between killing animals and killing people. For in relation to an animal's interests, as I have now described them, the traditional Epicurean arguments about death are correct. That is, there is no moment at which a cow can be badly off because of death, since (as Lucretius would put it) where death is, the cow isn't; ${ }^{48}$ and if there is no moment at which a cow is harmed by death, then it cannot be harmed by death at all. A premature death doesn't rob the cow of the chance to accumulate more momentary well-being, since momentary well-being isn't cumulable for a cow; nor can a premature death detract from the value of the cow's life as a whole, since a cow has no interest in its life as a whole, being unable to care about what sort of life it lives.

Of course, a person can care about what his life story is like, and a premature death can spoil the story of his life. Hence death can harm a person but it cannot harm a cow. 49

\section{University of Michigan}

Ann Arbor, Michigan

\section{NOTES}

1 For comments on earlier drafts of this paper, I am indebted to Elizabeth Anderson, Fred Feldman, Jonathan Lear, Brian Leiter, Peter Railton, Connie Rosati, Michael Slote, and Nicholas White.

2 In this paper I assume that a person's welfare is defined by his interests, or what's good for him. According to some theories of the good, however, a person can have interests that do not bear on his well-being, since his interests are not all self-regarding, and his wellbeing depends only on the fulfillment of self-regarding interests. These theories imply that what has value for a person and what improves that person's welfare are not necessarily coextensive.

In my view, proponents of such theories should recognize two distinct ways of measuring the relational value attaching to a person's life: first, the extent to which the life fulfills the 
person's interests, broadly construed; and second, the extent to which the life fulfills the person's self-interest, or welfare interests. Although I ignore this distinction, I believe that it could be introduced into my arguments with only a loss of simplicity.

(Thanks to Peter Railton for bringing this point to my attention.)

3 Henceforth I shall frequently drop the modifier and speak simply about the value of someone's life. In all cases, however, I shall be referring to the welfare value of the life-that is, how well it goes for the person living it-rather than to its being morally praiseworthy, aesthetically pleasing, or endowed with significance. (See also notes 8 and 18 below.) I shall also refer to the welfare value of someone's life as his "lifetime well-being."

4 Amartya Sen interprets the phrase 'being well off' as referring to something other than well-being. "The former," he says, "is really a concept of opulence" ("Well-Being and Freedom," the second lecture in "Well-Being, Agency and Freedom: The Dewey Lectures 1984," Journal of Philosophy (1985), 82: 195 ff.). Without necessarily rejecting Sen's intuitions about the meanings of these terms in ordinary parlance, I shall stipulate, for the purposes of the present paper, that 'being well off' refers to the state of having well-being.

5 This statement requires one minor qualification. I can imagine a kind of life whose welfare value would be determined by the amount of momentary welfare accruing to its subject. This would be a life with virtually no narrative structure at all-say, the life of someone who is maintained, from birth to death, in a state of semiconsciousness and inactivity. That this particular life would be only as good as the sum of its good and bad moments is perfectly compatible with my claim that a life's value is not in general a function of momentary well-being.

6 I believe that James Griffin denies additivity in this sense. He initially says, "We can never reach final assessment of ways of life by totting up lots of small, short-term utilities. ... It has to take a global form: this way of living, all in all, is better than that" (WellBeing: Its Meaning, Measurement and Moral Importance (Oxford: Clarendon Press, 1986), pp. 34-35). But Griffin then goes on to say that the values of a life's components should be assessed in terms of the components' contributions to the value of the whole, in such a way that "aggregation" is preserved (see esp. p. 36). Thus, Griffin's objection to the "totting-up model," as he calls it, is an objection to computing values by composition rather than decomposition. (See also pp. 88, 104-105, 144-146.)

7 The notion that the value of a life depends on its narrative structure appears in many works, including Alasdair MacIntyre's After Virtue (Notre Dame: University of Notre Dame Press, 1984), Chapter 15; and Charles Taylor's Sources of the Self: The Making of the Modern Identity (Cambridge: Harvard University Press, 1989), pp. $47 \mathrm{ff}$.

8 Michael Slote has pointed out to me that my view is at risk of being confused with a view sometimes attributed to Nietzsche, to the effect that literary or aesthetic considerations determine the value of a life. (See Alexander Nehamas, Nietzsche: Life as Literature (Cambridge: Harvard University Press, 1985).) I am grateful to Brian Leiter for guidance on this subject.

9 Our preferences among trends in well-being are not confined to that for improvement over deterioration. I think that one may have reason to prefer variety and intensity to consistency and moderation-that is, a life of great joys and sorrows to one of uninterrupted contentment-even if the sum of momentary well-being were the same in both lives; or there may be reasons supporting the opposite preference. (Amartya Sen favors equality of well-being among the different moments in one's life. See "Utilitarianism and Welfarism," Journal of Philosophy (1970), 76, pp. 407 f.). As I have said, my argument doesn't depend on showing one such preference to be more rational than another. I am arguing against a view that would deny the possibility of reasons supporting either preference, given the equal amounts of momentary well-being accumulated in the two lives.

10 The point made in this paragraph is borrowed from Connie Rosati, who makes it in a somewhat different context. See her "Mortality, Agency, and Regret" (forthcoming). 
Rosati has pointed out to me that people sometimes regret having started too late on a particular career or relationship, as if the value of their lives has been permanently reduced by this delay in their success or happiness. But I am not committed to denying that there can ever be a bad start that permanently depresses the value of one's life. I am committed only to denying that early misfortunes necessarily depress the value of one's life, as they necessarily would if well-being were additive.

What's more, I suspect that the view of well-being as additive cannot properly account for the cases that Rosati has in mind. What these people regret is not the level of well-being that they enjoyed in youth but rather their delay in embarking on a particular project that (as they now realize) will provide an important theme or plot for their life's story. Hence their regrets can be understood only as an attitude toward the narrative structure of their lives.

11 In Goods and Virtues (Oxford: Clarendon Press, 1983), originally published in Pacific Philosophical Quarterly (1982), 63: 311-326. Recently the additivity of well-being has also been challenged by John Bigelow, John Campbell, and Robert Pargetter, in "Death and Well-Being" (Pacific Philosophical Quarterly (1990), 71: 119).

Nick White has pointed out to me that an early argument against the additivity of wellbeing appears in C.I. Lewis's An Analysis of Knowledge and Valuation (La Salle, IL: Open Court Publishing Co., 1946), Chapter XVI. In reading Lewis, I have difficulty separating (1) the claim that the juxtaposition of events in a life affects the value of the whole; (2) the claim that it affects the intrinsic character of the events themselves, which are colored by the recollection and anticipation of other events; and (3) the claim that the value of a life depends on its character as a diachronic experience that is not reducible to a succession of momentary experiences. My defense of (1) does not depend on claims like (2) or (3). My argument can thus be viewed as a generalization of Lewis's, in which I abstract from Lewis's experiential conception of value.

12 Pp. 23-24.

13 E.g., when saying that "a good may itself be greater for coming late rather than early in life" (ibid., p. 25).

14 The Methods of Ethics (Indianapolis: Hackett Publishing Co., 1981), p. 381.

15 P. 23.

16 Here I am assuming that the veil of ignorance deprives the subject of information about his current age. For if he knew that he was currently in his forties, then he may have a preference arising out of what Parfit calls the bias toward the future (Reasons and Persons (Oxford: Clarendon Press, 1984), pp. 165 ff.). Note, then, that the time preferences considered by Slote are different in structure from those considered by Parfit. Parfit is concerned with a preference between past and future, whereas Slote is concerned with a preference between early and late. As the subject's temporal relation to an event changes, the former preference yields a different attitude toward the event, but the latter does not.

Connie Rosati has suggested to me that a person might prefer earlier success because it would be a sign of genius. But this suggestion strikes me as only proving my point. The person so described would not prefer earlier success merely by virtue of its timing; he would prefer it only because he values the meaning of some story that its early occurrence would subserve.

17 Bigelow, Campbell, and Pargetter also express doubts about Slote's treatment of this case. See "Death and Well-Being," pp. 122-123.

18 To say that the meaning of an event determines its contribution to the value of one's life is not to equate a valuable life with a meaningful one. To be sure, meaningfulness is a valuable characteristic in a life, and it, too, is probably a function of the life's narrative structure. But we can conceive of meaningful lives that aren't particularly good ones for the people who live them; and we may be able to conceive of good lives that aren't particularly meaningful. What's more, the meaning, or narrative role, that determines an event's 
contribution to a life's value, in my view, must not be confused with the event's meaningfulness, in the evaluative sense. To say that a particular increment in momentary well-being adds more to the value of a particular life if it has the meaning of a well-earned reward than that of a windfall is not to say that rewards are necessarily more meaningful events; it's simply to say that their contribution to the life's value depends on their being rewards.

19 Here I disagree with Bigelow, Campbell, and Pargetter, who believe that the value of someone's life, though not reducible to the sum of the momentary well-being enjoyed throughout that life, nevertheless supervenes on the pattern of the person's momentary well-being through time. (See "Death and Well-Being," pp. 127-128, 136-137.) Indeed, these authors believe that momentary well-being just is that property-whatever it may be-whose profile through time determines the value of a person's life (ibid., p. 128). My reasons for rejecting this view are expounded in greater detail below.

20 In some cases, of course, what we hope to learn from a misfortune is how to avoid repeating some mistake that occasioned it. But why do we think it more important to learn how to avoid repeating a past mistake than to learn a different lesson, about how to avoid committing a novel mistake? The reason isn't that we regard the consequences of a repeated mistake as necessarily worse than those of a mistake committed for the first time. We might prefer committing a novel mistake to repeating a past mistake even if their consequences would be equally bad. Surely, the reason is that we regard the story of committing the same mistake repeatedly as worse than that of committing different mistakes-a value judgment that depends on more than the momentary costs of the mistakes themselves.

One might think that our interest in learning from misfortunes, and the mistakes that occasion them, is based on the assumption that the mistakes a person has already committed are the ones that he's most likely to commit in future, and hence that lessons learned from them are the ones that are most likely to be useful. I disagree. We value learning from mistakes even if we know that the opportunity to repeat them will never arise. And we value learning from misfortunes, such as grave illnesses or freak accidents, that are not in any way attributable to mistakes.

Finally, one might think that learning from a misfortune is valuable only because it is a means to a more pleasant consciousness of the misfortune-a means of "coming to terms" or "making peace" with it. But why not simply forget about the misfortune entirely, or turn one's thoughts to something else? If making peace with a misfortune were valuable only as a means to pleasurable consciousness, then any alternative pleasure would serve just as well. Making peace with a misfortune is valuable not just because it entails acquiring so much peace of mind but because it entails acquiring peace of mind in a way that draws a fitting conclusion to one's past.

(All of the objections considered in this note were suggested to me by Connie Rosati.)

21 Charles Taylor remarks on our concern for whether the past "is just 'temps perdu' in the double sense intended in the title of Proust's celebrated work, that is, time which is both wasted and irretrievably lost, beyond recall, in which we pass as if we had never been" (Sources of the Self, p. 43). Taylor goes on to say that our desire to prevent the present from becoming lost in this sense is a desire for "the future to 'redeem' the past, to make it part of a life story which has sense or purpose." Taylor continues: "A famous, perhaps for us moderns a paradigm, example of what this can mean is recounted by Proust in his $A$ la recherche $d u$ temps perdu. In the scene in the Guermantes's library, the narrator recovers the full meaning of his past and thus restores the time which was 'lost' in the two senses I mentioned above. The formerly irretrievable past is recovered in its unity with the life yet to live, and all the 'wasted' time now has a meaning, as the time of preparation for the work of the writer who will give shape to this unity" (pp. 50-51).

22 Of course, we can also imagine a life in which an unsuccessful first marriage teaches you lessons instrumental to the success of your second. But in that case, I would claim, your life would be better than it would have been if the first marriage had been a dead loss. 
23 Peter Railton has pointed out to me that I seem to be appealing to a desire that was omitted from my calculation of desire-fulfillment-namely, your desire for a life in which your efforts are rewarded. But I do not think that your desire for a life in which your efforts are rewarded is contingent on the assumption of your having that desire in the life under consideration.

24 These philosophers include Joel Feinberg (Harm to Others (New York: Oxford University Press, 1984), pp. 79 ff.); and Bigelow, Campbell, and Pargetter ("Death and Well-Being," pp. 134-135, 138). Note that in rejecting the notion of retroactive effects on a person's momentary well-being, I do not necessarily reject the notion that the value of a person's life can be influenced by events after his death. The reason is that I regard the value of a person's life as a feature of his life story, and a person's life story may not end at his death.

25 Indeed, I don't see how Feinberg or Bigelow et al. can say that such a person's life gets better at all if, in adulthood, he desires that his youth had gone differently.

26 Many philosophers have noted the absence of any rational requirement to satisfy desires that one had in the past (Derek Parfit, Reasons and Persons, Chapter 8; Richard Brandt, "Two Concepts of Utility," in The Limits of Utilitarianism, ed. by Harlan B. Miller and William H. Williams (Minneapolis: University of Minnesota Press, 1982), p. 180). To my knowledge, these philosophers do not raise the further question of why one has any present reason to promote the fulfillment of one's desires for the future, given that one may have no reason to promote their fulfillment at the time. See also Amartya Sen, "Plural Utility," Proceedings of the Aristotelian Society (1981), 81: 202-204.

27 C.I. Lewis offers many suggestive remarks to the effect that striving and achieving have value only as related to each other in a diachronic whole (Analysis of Knowledge and Valuation, pp. 498 ff.). As I have noted, however, Lewis's remarks often rely on the notion that the experiences of striving and achieving suffuse one another or add up to an irreducible diachronic experience.

${ }^{28}$ Subsequently, such constraints may relax to some extent, since the events of one's retirement may be less intimately related to the other events in one's life than those occurring at the culmination of one's active career. A life story that has only one fitting climax may have more than one fitting denouement.

29 As Michael Stocker points out, the value of a life is what Moore would have called an “organic whole," Plural and Conflicting Values (Oxford: Clarendon Press, 1990), pp. 300-302, 323.

30 The same goes for Bigelow, Campbell, and Pargetter, who argue that the value of someone's life supervenes on the pattern of his momentary well-being through time. They say, "Surely if two people have had the same temporal well-being at all times of their lifespans of equal length, they are to be seen to have had equal global well-being" ("Death and Well-Being," p. 137). I say, Surely not. For if one person's later good fortune redeemed his earlier sufferings and the other's did not, the value of their lives might well differ.

31 Herodotus, I. 30-33. This story is cited by Aristotle (Nicomachean Ethics I.x.1-2), whose final definition of happiness (at I.x.15) also betrays an inclination to agree with Solon to some extent.

32 Some philosophers seem to regard 'prudence' as synonymous with "self-interested rationality" or "practical wisdom." In this paragraph I am discussing prudence in a narrower sense, in which it denotes a specific aspect of practical wisdom-namely, a rational attitude toward the future.

33 For a clear presentation of this view, see Fred Feldman, "Some Puzzles About the Evil of Death," forthcoming in The Philosophical Review. Feldman's own view on the matter may not correspond to the view that he presents in this paper, since the paper adopts a simplistically additive hedonism merely for the sake of arguing with Epicureans. What Feldman does believe is that the evil of a particular death must be computed as the 
difference between the value of the actual life in which it occurs and that of the same life in the nearest possible world in which the death doesn't occur. I do not in general accept this method of computing the value of events in someone's life, since I believe that events have a momentary value that's distinct from their contribution to the value of the subject's life as a whole. Since death has no momentary disvalue, however, my view about it coincides with Feldman's. I discuss this subject further below.

34 Griffin expresses doubts about this view in note 33, p. 355, of Well-Being.

35 See Griffin, Well-Being, pp. 36, 144-146.

36 In speaking of financial well-being, of course, I am assuming that wealth has intrinsic value for a person. Nothing in my argument depends on this assumption. Emotional, social, or physical well-being can be substituted in my arguments, mutatis mutandis, for financial well-being.

37 Assessments of emotional, physical, and professional well-being thus involve what Sen would call "informational constraints"-that is, constraints on which sorts of information are relevant. In Sen's terms, the reason why people with equivalent financial holdings have the same level of financial well-being is that they belong to the same "isoinformation set" as defined by the applicable informational constraint. See "Moral Information," the first lecture in "Well-Being, Agency and Freedom," pp. 169-184.

38 For ease of expression, I have chosen to compare probabilities on a logarithmic scale. That is, I call $p$ doubly unlikely in relation to $q$ if the probability of $p$ is equal to the probability of $q$ squared.

39 See the preceding note.

40 This argument is in the same spirit as the following remarks of Thomas Nagel's: "Human beings are subject to . . . motivational claims of very different kinds. This is because they are complex creatures who can view the world from many perspectives ... and each perspective presents a different set of claims. Conflict can exist within one of these sets, and it may be hard to resolve. But when conflict occurs between them, the problem is still more difficult. . . . [Such conflicts] cannot, in my view, be resolved by subsuming either of the points of view under the other, or both under a third. Nor can we simply abandon any of them. There is no reason why we should. The capacity to view the world simultaneously from [different points of view] is one of the marks of humanity" ("The Fragmentation of Value," in Mortal Questions (Cambridge: Cambridge University Press, 1979), p. 134). (Here I have made strategic deletions from Nagel's remarks in a way that may exaggerate their similarity to my view.)

${ }^{41}$ I am therefore making a somewhat different point from one made by Bernard Williams. When Williams says, "The correct perspective on one's life is from now," he is criticizing the principle that one should "distribute consideration equally over [one's] whole life" ("Persons, Character and Morality," in The Identities of Persons, ed. by Amélie Oksenberg Rorty (Berkeley: University of California Press, 1976), pp. 209, 206).

42 Kurt Vonnegut, Slaughterhouse Five (New York: Dell Publishing, 1969), p. 23: "The Tralfamadorians can look at all the different moments just the way we can look at a stretch of the Rocky Mountains . . . . They can see how permanent all the moments are, and they can look at any moment that interests them. It is just an illusion we have here on Earth that one moment follows another one ...."

43 C.I. Lewis also defends the autonomy of momentary value (Analysis of Knowledge and Valuation, pp. $503 \mathrm{ff}$.). Again, Lewis's argument is based on an experiential conception of value.

44 I defend this view in "An Essay on Internalism" (manuscript). Note that internalism applies only to matters of intrinsic value. Obviously, something that's beyond a person's powers of comprehension can still be good for him extrinsically, since it can be conducive to things that are good for him intrinsically.

45 Of course, the intuition expressed here may not be independent of that expressed in 
internalism. Indeed, there are some interpretations of internalism according to which the two intuitions are one and the same. I separate them here because I regard internalism as resting on a rather different intuition. See my "Essay on Internalism."

46 This point follows most clearly from desire-based conceptions of well-being, which will define how valuable different sequences of harms and benefits are for a cow in terms of how much the cow wants those sequences, or would want them under some ideal conditions. Since a cow cannot care about sequences of harms and benefits, and wouldn't be able to care about them except under conditions that transformed it into something other than a cow, these definitions imply that temporal sequences cannot be assigned a value specifically for a cow.

Although my point thus follows from desire-based conceptions of relational value, it does not presuppose that relational value is desire-based. Judgments of relational value must somehow be relativized to the subject's perspective-if not by being made to depend on the subject's actual or counterfactual desires, then by some other means. And any strategy for relativizing evaluations of temporal sequences to the perspective of a cow will run into the same obstacle-namely, that the perspective of a cow doesn't encompass temporal sequences at all.

(One might think that Peter Railton's version of the desire-based conception would have the resources to circumvent this problem, since it would define what's good for the cow in terms of what an idealized cow would want its actual self to desire ("Moral Realism," The Philosophical Review (1986), 95: 163). The idealized cow, one might think, could acquire the ability to conceive of, and form preferences among, temporal sequences of harms and benefits while still doing so on behalf of its cognitively limited and hence fully bovine self. This suggestion strikes me as out of keeping with Railton's theory, for various reasons, of which one will suffice for now. The cognitively enhanced cow, once fully informed, would realize that its actual self was unable to want temporal sequences of harms and benefits, and would therefore not bother wanting its actual self to have any such desires.)

47 See Griffin, Well-Being, p. 145: "Even when one does tot up, say, many small-scale pleasures to get an overall aggregate value, the value of the life containing these many local pleasures is fixed in comparison with competing forms of life, and so the finally effective magnitudes are fixed by global desires." My point is that a cow is incapable of having the requisite global desires.

48 De Rerum Natura, III, 870 f., 898 f., cited by Bernard Williams in "The Makropulos Case," Problems of the Self (Cambridge: Cambridge University Press, 1973), p. 83, n. 2.

49 Here I am not saying that a premature death is bad for a person because he wants or would want his life to be longer. Rather, I am saying that because a person can want his life to be longer, the judgment that a premature death is bad for him satisfies the requirements of internalism. To cite a person's actual or potential desires as evidence that a value judgment is compatible with internalism is one thing; to cite those desires as the value judgment's truth-makers is quite another.

These brief remarks on the evil of death were inspired by Thomas Nagel's essay "Death," in Mortal Questions, 1-10. Nagel points out that the Epicurean argument assumes that if death harms its victim, it must harm him at a particular time. Nagel argues that this assumption is false. (So does Fred Feldman, in "Some Puzzles About the Evil of Death.") My claim is that although the assumption is indeed false in application to persons (which is the application that Nagel has in mind), it is true in application to lower animals. 